ARTICLE

https://doi.org/10.1038/s41467-019-10013-6

\title{
Gas reactions under intrapore condensation regime within tailored metal-organic framework catalysts
}

Iker Agirrezabal-Telleria ${ }^{1,4}$, Ignacio Luz ${ }^{2,4}$, Manuel A. Ortuño (D) ${ }^{3,4}$, Mikel Oregui-Bengoechea ${ }^{1}$, Iñaki Gandarias ${ }^{1}$, Núria López $\mathbb{B}^{3}{ }^{3}$, Marty A. Lail ${ }^{2}$ \& Mustapha Soukri ${ }^{2}$

Production of 1-butene, a major monomer in polymer industry, is dominated by homogeneous protocols via ethylene dimerization. Homogeneous catalysts can achieve high selectivity but require large amounts of activators and solvents, and exhibit poor recyclability; in turn, heterogeneous systems are robust but lack selectivity. Here we show how the precise engineering of metal-organic frameworks (MOFs) holds promise for a sustainable process. The key to the (Ru)HKUST-1 MOF activity is the intrapore reactant condensation that enhances ethylene dimerization with high selectivity (>99\% 1-butene) and high stability $(>120 \mathrm{~h})$ in the absence of activators and solvents. According to spectroscopy, kinetics, and modeling, the engineering of defective nodes via controlled thermal approaches rules the activity, while intrapore ethylene condensation accounts for selectivity and stability. The combination of well-defined actives sites with the concentration effect arising from condensation regimes paves the way toward the development of robust MOF catalysts for diverse gas-phase reactions.

\footnotetext{
${ }^{1}$ Department of Chemical and Environmental Engineering, Engineering School of the University of the Basque Country (UPV/EHU), Plaza Torres Quevedo 1, 48013 Bilbao, Spain. ${ }^{2}$ RTI International, 3040 E Cornwallis Road, Research Triangle Park, NC 27709, USA. ${ }^{3}$ Institute of Chemical Research of Catalonia (ICIQ), The Barcelona Institute of Science and Technology (BIST), Av. Països Catalans 16, 43007 Tarragona, Spain. ${ }^{4}$ These authors equal contribution: Iker Agirrezabal-Telleria, Ignacio Luz, Manuel A. Ortuño. Correspondence and requests for materials should be addressed to I.A-T. (email: iker.aguirrezabal@ehu.eus) or to M.A.O. (email: mortuno@iciq.es) or to M.S. (email: msoukri@rti.org)
} 
inear a-olefins, derived from light alkene oligomerization reactions, are broadly used as lubricants and co-monomers in polymer synthesis, and represent one of few examples for which homogeneous catalysts ${ }^{1}$ are still employed in bulk chemical production. Transition-metal compounds selectively convert light alkenes into industrially-relevant products ${ }^{2}$, but their limited recyclability and excessive use of solvent and activators present environmental and economic limitations. The search for robust heterogeneous catalysts is still a challenge as they do not show well-defined sites and lack the high selectivity reported for homogeneous counterparts.

Metal-organic frameworks (MOFs) ${ }^{3}$ hold promise to get the best ingredients from both worlds, i.e., selective and well-defined catalytic sites distributed on porous solids ${ }^{4-6}$. While typical pristine MOFs are hardly reactive during ethylene dimerization, recent advances in defect-engineering synthetic methods enable tailoring a broad range of lattice defects that enhance catalytic activity $^{7-11}$. However, there are several challenges to render these materials into practice in large-scale processes. For instance, remarkable ethylene dimerization turnovers were obtained using $\mathrm{Ni}$-containing MOFs ${ }^{12-20}$, but they still require large amounts of activators (up to 500 equivalents per active metal) to generate the active species. Moreover, the Ni-MOF catalysts undergo fast deactivation ${ }^{12}$. Given the narrow channels in MOFs, we propose the use of intrapore reactant condensation ${ }^{21}$ to provide catalyst stability during gas-phase reactions at mild temperatures.

Here, we present heterogeneous catalysis and defect synthesis methods for $(\mathrm{Ru})$ HKUST-1 that allow controlled defect engineering and present unique activity, selectivity, and stability in ethylene dimerization. The thermal engineering of defects yields catalytically active species with remarkable activity in the absence of activators, high selectivity to 1-butene ( $>99 \%$ selectivity), and long-time stability $(>120 \mathrm{~h})$ under intrapore ethylene condensation regime. We prove that active $\mathrm{Ru}-\mathrm{H}$ sites created through economic and versatile thermal approaches behave the same as those prepared via conventional ligand-engineered methods. Kinetic, spectroscopic, and theoretical methods provide new insights on the nature and concentration of catalytic sites and demonstrate the kinetic consequences of intrapore reactant condensation on the stability of MOF catalysts. The exquisite control over well-defined active sites combined with intrapore liquid regime opens new research opportunities to develop heterogeneous porous systems that work at wider temperature ranges than those under liquid phase.

\section{Results}

Ligand-engineered defective MOF catalysts. In order to tailor an active and stable MOF catalyst for ethylene dimerization, we chose the $(\mathrm{Ru})$-HKUST-1 material, which is amenable to include lattice defective sites without compromising the framework structure (Fig. 1) 7,22. Previously, defective (Ru)HKUST-1, prepared via controlled in-synthesis incorporation of coordinatively deficient pyridine-3,5-dicarboxylate ligands, led to the formation of robust metal-hydride species upon $\mathrm{H}_{2}$ exposure at $150{ }^{\circ} \mathrm{C}^{23,24}$. Inspired by these results, we propose a new experimental set up where such defective MOFs can efficiently catalyze ethylene dimerization in the absence of activators.

Here we use direct catalytic evidences to learn on ethylene dimerization site requirements in (Ru)HKUST-1 MOFs containing $25 \%$ of pyridine-3,5-dicarboxylate linkers, namely $\mathrm{MOF}_{\mathrm{L} 25}$. Figure $2 \mathrm{a}$ shows ethylene dimerization turnover frequencies (TOFs) vs. time on stream at $50{ }^{\circ} \mathrm{C}$ using different pre-treated $\mathrm{MOF}_{\mathrm{L} 25}$. As discussed later, we consider one active $\mathrm{Ru}$ atom per defective node to calculate TOF values. The reaction pressure $(4.2 \mathrm{MPa})$ and temperature $\left(50^{\circ} \mathrm{C}\right)$ conditions in Fig. $2 \mathrm{a}$ lead to

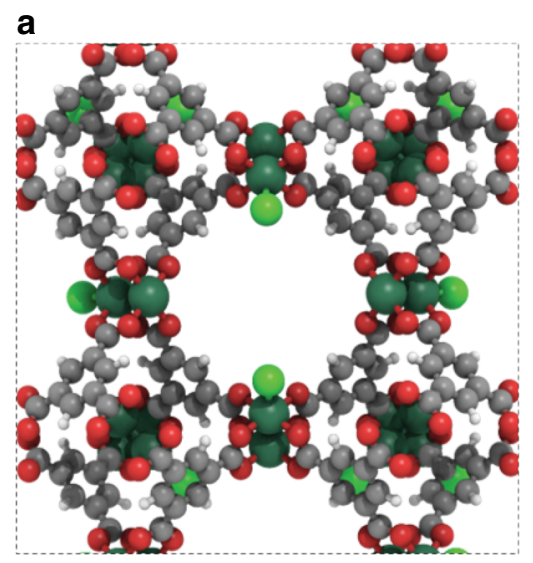

b

Fig. 1 Structure of (Ru)HKUST-1 metal-organic framework. a Periodic structure of pristine (Ru)HKUST-1 with a pore size of $1.5 \mathrm{~nm}$. b Paddlewheel node of pristine (Ru)HKUST-1. c Paddle-wheel node of defective (Ru)HKUST-1. (Ru = dark green, $\mathrm{Cl}=$ green, $\mathrm{O}=$ red, $\mathrm{N}=$ blue, $\mathrm{C}=$ grey, $\mathrm{H}=$ white)

the remarkable stabilization of active species, facilitated by the intrapore condensation of ethylene reactants within $\mathrm{MOF}_{\mathrm{L} 25}$, as discussed in next sections. After $\mathrm{N}_{2}$ treatment at $200^{\circ} \mathrm{C}$ to remove labile adsorbates (purple line), $\mathrm{MOF}_{\mathrm{L} 25}$ exhibits dimerization activity after an induction period with $99 \%$ selectivity to 1-butene (Fig. 2a). Slow induction periods reflect the limited capacity of ethylene to form active $\mathrm{Ru}-\mathrm{H}$ species at dimerization conditions $\left(50^{\circ} \mathrm{C}\right)$. Interestingly, further exposure to $\mathrm{H}_{2}$ at $150{ }^{\circ} \mathrm{C}$ (blue line) produces a catalyst with initial rates one order of magnitude higher than those found previously ${ }^{24}$, while maintaining high selectivity (Supplementary Fig. 7). The catalytic differences in Fig. $2 \mathrm{a}$ are attributed to the facile formation of $\mathrm{Ru}-\mathrm{H}$ species in ligand-engineered open metal sites under $\mathrm{H}_{2}$ atmosphere at $150^{\circ} \mathrm{C}$ (vide infra). The generation of $\mathrm{Ru}-\mathrm{H}$ species is optimized at $150{ }^{\circ} \mathrm{C}$ in $\mathrm{H}_{2}$ without involving the degradation of the porous framework (see $\mathrm{N}_{2}$ physisorption in Supplementary Fig. 2). Higher pre-treatment temperatures $\left(200^{\circ} \mathrm{C}\right.$ in $\left.\mathrm{H}_{2}\right)$ lead to complete MOF degradation into metallic $\mathrm{Ru}$ particles (Supplementary Fig. 4). The catalytic role of $\mathrm{Ru}-\mathrm{H}$ species is supported by quenching under oxidizing environments $\left(\mathrm{O}_{2}\right.$ at $150{ }^{\circ} \mathrm{C}$, orange line in Fig. 2a), leading to inactive $\mathrm{Ru}$ species and induction periods in contact with ethylene. The results in Fig. 2a show compelling evidences on the role of $\mathrm{Ru}-\mathrm{H}$ species in ligandengineered defective MOFs to achieve stable alkene dimerization turnovers in the absence of co-catalysts and solvents.

To evaluate the $(\mathrm{Ru}) \mathrm{HKUST}-1$ pre-treatment effects in ethylene dimerization (Fig. 2a), we turn to IR spectroscopy. Figure $2 b$ shows in-situ IR spectroscopic data of $\mathrm{MOF}_{\mathrm{L} 25}$ after successive gas pre-treatments. The two bands at 2059 and $1978 \mathrm{~cm}^{-1}$ after $\mathrm{N}_{2}$ and $\mathrm{H}_{2}$ (purple and blue lines) are characteristic of $\mathrm{Ru}-\mathrm{H}$ species, as reported in literature ${ }^{23}$. Periodic density functional theory (DFT) calculations evidence the facile formation of $\mathrm{Ru}-\mathrm{H}$ species via a heterolytic $\mathrm{H}-\mathrm{H}$ bond breaking process under $\mathrm{H}_{2}$ atmosphere (Supplementary Fig. 27) ${ }^{25-27}$. After CO exposure (green line), $\mathrm{MOF}_{\mathrm{L} 25}$ exhibits two additional intense stretching vibrations at 2082 and $2015 \mathrm{~cm}^{-1}$, which correspond to single carbonyl species bonded to $\mathrm{Ru}^{2+}$ and $\mathrm{Ru}^{+\delta}$. The latter were previously identified as partially reduced $\mathrm{Ru}(0<\delta<2)^{23,28}$. Moreover, a $\mathrm{C}=\mathrm{O}$ stretching band appears at $1656 \mathrm{~cm}^{-1}$, which is assigned to $\mathrm{Ru}(\mathrm{II})$-formyl species ${ }^{29}$ coming from $\mathrm{CO}$ reduction via $\mathrm{Ru}-\mathrm{H}$. Even after $\mathrm{N}_{2}$ purging at $30^{\circ} \mathrm{C}$, these $\mathrm{CO}$-adsorbed species are stable, suggesting the remarkable binding strength of $\mathrm{CO}$ to $\mathrm{Ru}$ species. At $30^{\circ} \mathrm{C}$, IR spectra rule out the presence of either sym-/asymmetric $\mathrm{Ru}(\mathrm{CO})_{2}$ gem-dicarbonyl or $\mathrm{Ru}_{2}(\mathrm{CO})$ 

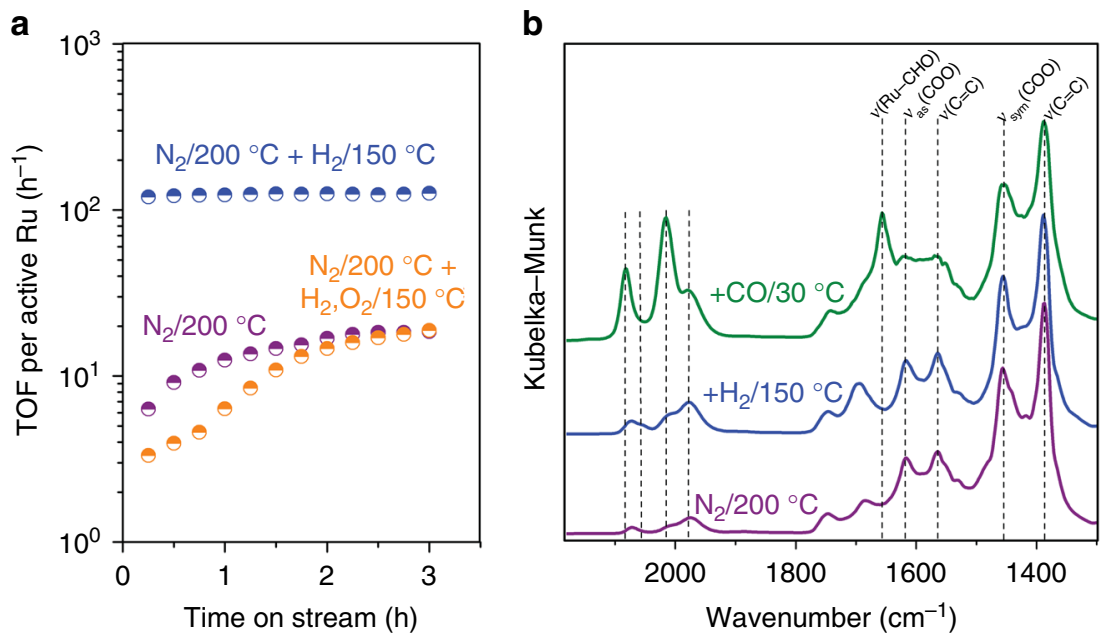

Fig. 2 Catalytic activity and formation of the Ru-H active site in $\mathrm{MOF}_{\mathrm{L} 25}$. a Ethylene dimerization TOFs at $50^{\circ} \mathrm{C}$ and $4.2 \mathrm{MPa}$ ethylene after activation of $\mathrm{MOF}_{\mathrm{L} 25}$ in $\mathrm{N}_{2}$ at $200^{\circ} \mathrm{C}$, in $\mathrm{N}_{2}$ at $200^{\circ} \mathrm{C}+\mathrm{H}_{2}$ at $150^{\circ} \mathrm{C}$, and in $\mathrm{N}_{2}$ at $200^{\circ} \mathrm{C}+\mathrm{H}_{2}$ at $150^{\circ} \mathrm{C}+\mathrm{O}_{2}$ at $150{ }^{\circ} \mathrm{C}$. Active Ru corresponds to one metal atom per defective node. b IR spectra after subsequent treatments for $\mathrm{MOF}_{\mathrm{L} 25}: \mathrm{N}_{2}$ at $200^{\circ} \mathrm{C}, \mathrm{H}_{2}$ at $150{ }^{\circ} \mathrm{C}$, and $\mathrm{CO}$ at $30^{\circ} \mathrm{C}$. All spectra are shown after $\mathrm{N}_{2}$ flushing

bridged-carbonyl species, as compared to $-80{ }^{\circ} \mathrm{C}^{23,30}$. DFTcomputed $\mathrm{C}=\mathrm{O}$ frequencies of $1950-2050 \mathrm{~cm}^{-1}$ for $\mathrm{CO}$ and $1600-1700 \mathrm{~cm}^{-1}$ for formyl are in line with experimental data (Supplementary Fig. 28). $\mathrm{MOF}_{\mathrm{L} 25}$ treated at $200^{\circ} \mathrm{C}$ in $\mathrm{N}_{2}$ also shows the bands that correspond to $\mathrm{Ru}-\mathrm{H}$ species, and their presence is also confirmed by the initial dimerization activity and the induction period in contact with ethylene at $50{ }^{\circ} \mathrm{C}$ (Fig. 2a). These evidences suggest that active $\mathrm{Ru}-\mathrm{H}$ species within the defects of (Ru)HKUST-1 can also be formed via thermal approaches in contact with $\mathrm{N}_{2}$ as discussed in the next section.

Thermal-engineered defective MOF catalysts. Based on the above-mentioned catalytic and spectroscopic evidences for $\mathrm{MOF}_{\mathrm{L} 25}$ (Fig. 2), together with a potential partial decarboxylation of linkers at high temperature ${ }^{31}$, we next examine the generation of defects and $\mathrm{Ru}-\mathrm{H}$ sites via a controlled thermal approach. We start from pristine (Ru)HKUST-1 without any pyridine-3,5dicarboxylate linkers, namely $\mathrm{MOF}_{\mathrm{L} 0}$, and evaluate thermal preactivation effects on ethylene dimerization activity (Fig. 3a). $\mathrm{MOF}_{\mathrm{L} 0}$ treated at $150{ }^{\circ} \mathrm{C}$ in $\mathrm{N}_{2}$ shows an induction period in contact with ethylene at $50{ }^{\circ} \mathrm{C}$ and $4.2 \mathrm{MPa}$. After thermal preactivation at $200^{\circ} \mathrm{C}$ in $\mathrm{N}_{2}, \mathrm{MOF}_{\mathrm{L} 0}$ exhibits greater initial rates than when treated at $150^{\circ} \mathrm{C}$, while maintaining selectivity. Temperature effects on ethylene dimerization activity are optimized for $\mathrm{MOF}_{\mathrm{L} 0}$ pre-treated at $300^{\circ} \mathrm{C}$, as the initial rates abruptly decrease when $\mathrm{MOF}_{\mathrm{L} 0}$ is pre-treated at $400^{\circ} \mathrm{C}$ in $\mathrm{N}_{2}$. Such catalytic differences inspired us to perform analogous pretreatment thermal experiments on $\mathrm{MOF}_{\mathrm{L} 0}$ via in-situ TGA-MS, $\mathrm{XRD}$, and IR. TGA analyses (Fig. 3b) quantify the number of generated defects (blue line), XRD determines the MOF structural stability (Fig. 3c), and IR experiments (Fig. 3d) evaluate the nature of the resulting defective site as a function of temperature. The proposed mechanism for the thermal generation of defects is supported by MS (Fig. 3b), which identifies the composition of released species.

$\mathrm{N}_{2}$-treatments up to $200{ }^{\circ} \mathrm{C}$ incorporate only ca. $5 \%$ of defects in $\mathrm{MOF}_{\mathrm{L} 0}$ (purple area, Fig. 3b) and induce carboxylate protonation, as indicated by the significant appearance of a new band in IR at $1698 \mathrm{~cm}^{-1}$ (purple line, Fig. 3d), assigned to the stretching of free carboxylic acids. Heating from 200 to $300{ }^{\circ} \mathrm{C}$ increases the defect concentration up to $38 \%$ on $\mathrm{MOF}_{\mathrm{L} 0}$ (orange area, Fig. 3b). In this range, a progressive attenuation of IR signals occurs for both symmetric carboxylates $\left[v_{\text {sym }}(\mathrm{COO})\right]$ and free carboxylic acids due to further release of $\mathrm{CO}_{2}$, while signals attributed to phenyl rings $[v(\mathrm{C}=\mathrm{C})]$ remain constant (orange line, Fig. 3d). Moreover, intense IR signals appear between 2100-1900 $\mathrm{cm}^{-1}$, which are assigned to $\mathrm{Ru}-\mathrm{CO}$ and $\mathrm{Ru}-\mathrm{H}$ stretching bands. Similar bands were observed in $\mathrm{MOF}_{\mathrm{L} 25}$ at $200^{\circ} \mathrm{C}$ (Fig. 2b), which contains a combination of ligandengineered (25.0\%) and thermal-engineered (8.2\%) defects (Supplementary Fig. 13). The presence of $\mathrm{Ru}-\mathrm{CO}$ and $\mathrm{Ru}-\mathrm{H}$ species at defective $\mathrm{Ru}$ sites is supported by the simultaneous release of $\mathrm{CO}_{2}$ and $\mathrm{CO}$ at $300{ }^{\circ} \mathrm{C}$ (Fig. 3b), which can originate from the catalytic rupture of formic acid ${ }^{32}$. These evidences suggest a consequent reduction of $\mathrm{Ru}$ atoms with temperature to compensate the charge over the MOF node, which is consistent with the release of $\mathrm{HCl}$ (Fig. 3b) and elemental analysis (Supplementary Table 2). A similar metal reduction via dehalogenation was reported for Fe-containing $\mathrm{MOF}^{33}$. XPS data (Supplementary Fig. 20) are also consistent with the reduction of $\mathrm{Ru}$ atoms and the dehalogenation process when $\mathrm{MOF}_{\mathrm{L} 0}$ is treated above $200^{\circ} \mathrm{C}$ in $\mathrm{N}_{2}$. Nevertheless, in-situ XRD data indicate the remarkable structural stability of the thermalengineered $\mathrm{MOF}_{\mathrm{L} 0}$ structure and the absence of $\mathrm{Ru}$ nanoparticles up to $300^{\circ} \mathrm{C}$ (orange line, Fig. 3c).

$\mathrm{N}_{2}$-treatments at $400{ }^{\circ} \mathrm{C}$ (green area, Fig. 3b) lead to nearly complete MOF decarboxylation (up to 95\%) and the consequent reduction of $\mathrm{Ru}-\mathrm{CO}$ and $\mathrm{Ru}-\mathrm{H}$ stretching bands (green line, Fig. 3d). These effects are consistent with the sintering of metallic $\mathrm{Ru}$ nanoclusters into larger crystalline domains at $400^{\circ} \mathrm{C}$, as supported by the appearance of a broad signal centered at 42 theta degree in XRD (green line, Fig. 3c). XPS data also support the advanced degree of $\mathrm{Ru}$ reduction (Supplementary Table 3 ) at $400{ }^{\circ} \mathrm{C}$, which leads to the fusion of phenyl rings into a carbonaceous matrix ${ }^{31}$.

The differences between the number of engineered defects and active $\mathrm{Ru}-\mathrm{H}$ species explain the activity trends observed in Fig. $3 \mathrm{a}$ as a function of thermal pre-treatment in $\mathrm{N}_{2}$. Compared to the more limited in-synthesis ligand engineering procedures, the thermal approach reveals a general and straightforward route to create active sites from as-synthesized $\mathrm{MOF}_{\mathrm{L} 0}$ without $\mathrm{H}_{2}$ activation. The active sites are the same in both cases but the thermal treatment, when properly controlled, is a much more appealing technique to design defect sites. Next, we will compare 
a

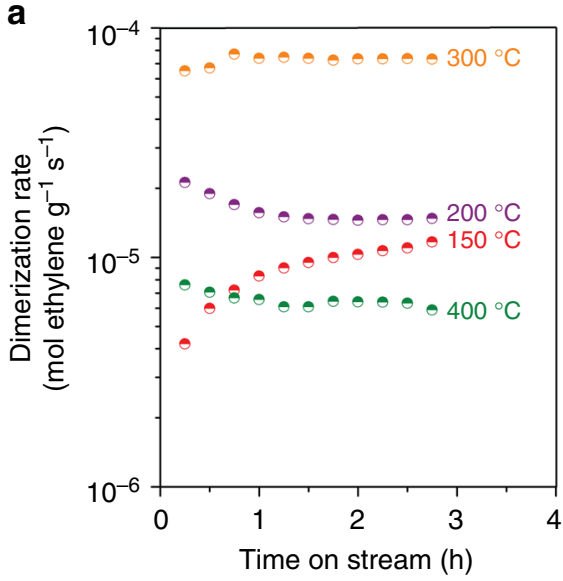

C

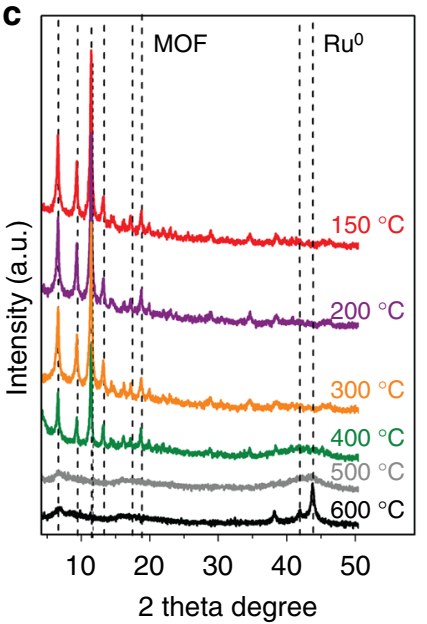

b

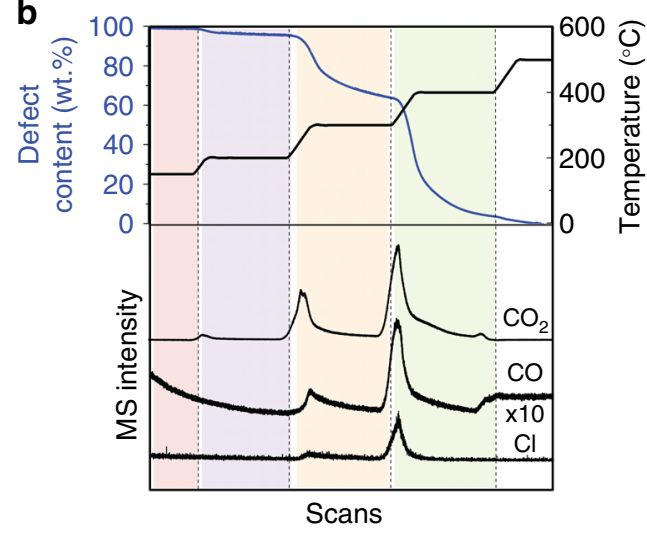

d

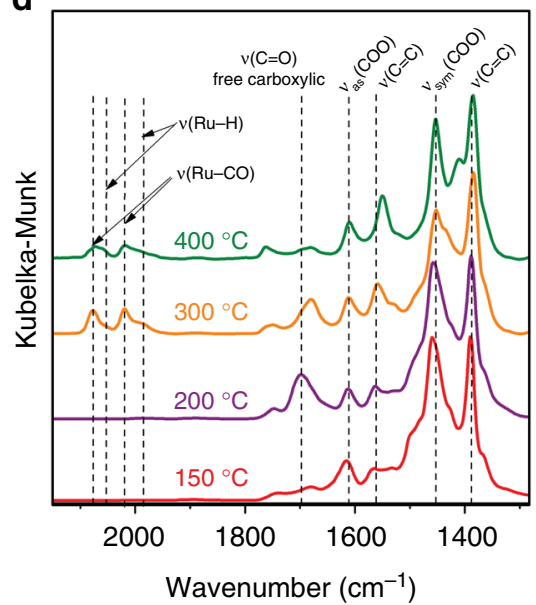

Fig. 3 Thermal treatment effects on activity, surface species, and structure of $\mathrm{MOF}_{\mathrm{LO}}$. a Ethylene dimerization rates at $50^{\circ} \mathrm{C}$ and $4.2 \mathrm{MPa}$ ethylene after

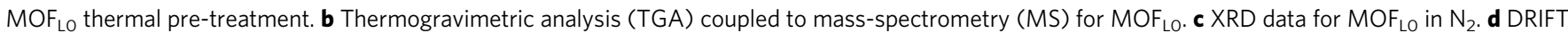
spectra of MOFLo in $\mathrm{N}_{2}$

this versatile procedure to conventional ligand engineering approaches as a function of defect content.

Role of defects in selective ethylene dimerization. In order to evaluate the influence of the type and number of defects on catalytic activity, we prepared and tested a series of ligand- and thermal-engineered MOFs. For ligand-engineered samples (\% of defects): $\mathrm{MOF}_{\mathrm{L} 10}(20.4 \%), \mathrm{MOF}_{\mathrm{L} 25}(33.3 \%)$, and $\mathrm{MOF}_{\mathrm{L} 50}(51.0 \%)$. For thermal-engineered samples (\% of defects): $\mathrm{MOF}_{\mathrm{L} 0}-200$ (5.0\%), $\mathrm{MOF}_{\mathrm{L} 0}-250$ (13.4\%), $\mathrm{MOF}_{\mathrm{L} 0}-300$ (38\%), $\mathrm{MOF}_{\mathrm{L} 0}-350$ (71.4\%), and $\mathrm{MOF}_{\mathrm{L} 0}-400$ (95.0\%).

Figure $4 \mathrm{a}, \mathrm{b}$ plot ethylene dimerization TOFs per total $\mathrm{Ru}$ in the MOF and per active Ru sites, respectively, as a function of measured defect contents for ligand- (blue) and thermalengineered (green) MOFs. Figure 4a shows a volcano shape with a maximum TOF regardless of the method employed to create defects. The increase in activity parallels the higher concentration of active sites (the active $\mathrm{Ru}$ /total $\mathrm{Ru}$ fraction increases), but there is a maximum to the incorporation of active sites without compromising the mechanical stability. When defects are above $40 \%$, partial amorphization for ligand-engineered samples $\left(\mathrm{S}_{\mathrm{BET}}\right.$ decreased from $974 \mathrm{~m}^{2} / \mathrm{g}$ for $\mathrm{MOF}_{\mathrm{L} 25}$ to $668 \mathrm{~m}^{2} / \mathrm{g}$ for $\mathrm{MOF}_{\mathrm{L} 50}$, Supplementary Fig. 1) causes smaller dimerization TOFs. Such decrease in TOFs for thermal-engineered catalysts is also attributed to the aggregation of $\mathrm{Ru}$ into larger inactive particles (Fig. 3c). This latter hypothesis is confirmed by testing the catalytic activity of $\mathrm{Ru}$ nanoparticles embedded on a carbonaceous matrix prepared at $500{ }^{\circ} \mathrm{C}$ under $\mathrm{N}_{2}$ (Supplementary Fig. 24), which show no ethylene dimerization products. Figure $4 \mathrm{~b}$ displays a plateau at low defect content, suggesting that the nature of active sites in both ligand- and thermal-engineered MOFs is the same and that they behave as single ensemble catalysts. In-situ FTIR data indicate the presence of bound ethyl intermediates when MOF catalysts are exposed to ethylene (Supplementary Fig. 10). The optimized $\mathrm{MOF}_{\mathrm{L} 25}$ catalyst presents a TOF of $c a .200 \mathrm{~h}^{-1}$, which is comparable to related gas-phase systems under flow conditions: $16^{14}, 252^{13}$, and $1570^{12} \mathrm{~h}^{-1}$ (Supplementary Table 4).

To get insights on the reaction mechanism and selectivity to dimers, we turn to computational modeling at periodic DFT level (see Computational Details). We use a unit cell of ca. $26 \times 26 \times 26$ $\AA^{3}$, which prevents a spurious concentration of defect sites when computing periodic images. Benchmark calculations indicate that PBE-D2 is suitable to describe the electronic structure of $(\mathrm{Ru})$ HKUST-1 (Supplementary Table 5). We computed the ethylene dimerization via a Cossee-Arlman mechanism ${ }^{15,34,35}$ using a ligand-engineered defective node. Figure $4 \mathrm{c}$ shows the model L-1 used in the simulations (Supplementary Fig. 26) and the reaction profile in blue. From the active $\mathrm{Ru}-\mathrm{H}$ species 3 , ethylene binds to $\mathrm{Ru}$ forming 5 with an adsorption energy of $0.89 \mathrm{eV}$. Species 5 undergoes insertion via TS5 with a relative energy barrier of $0.26 \mathrm{eV}$. The resulting ethyl species binds a second ethylene as in 7 , which inserts into the $\mathrm{Ru}-\mathrm{C}$ bond via TS7 with 
a

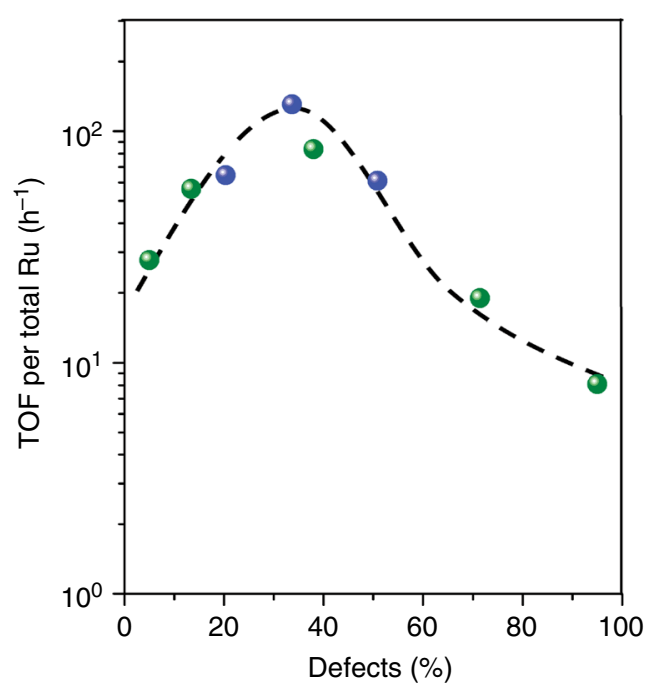

b

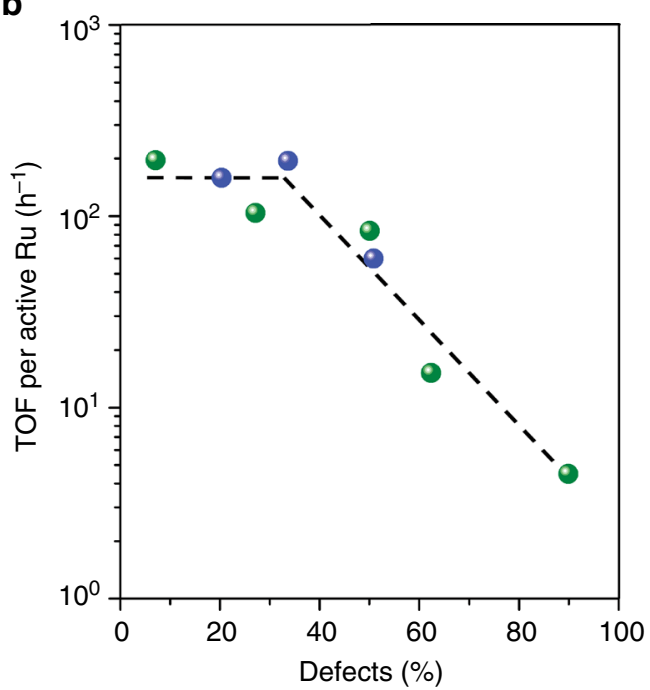

C
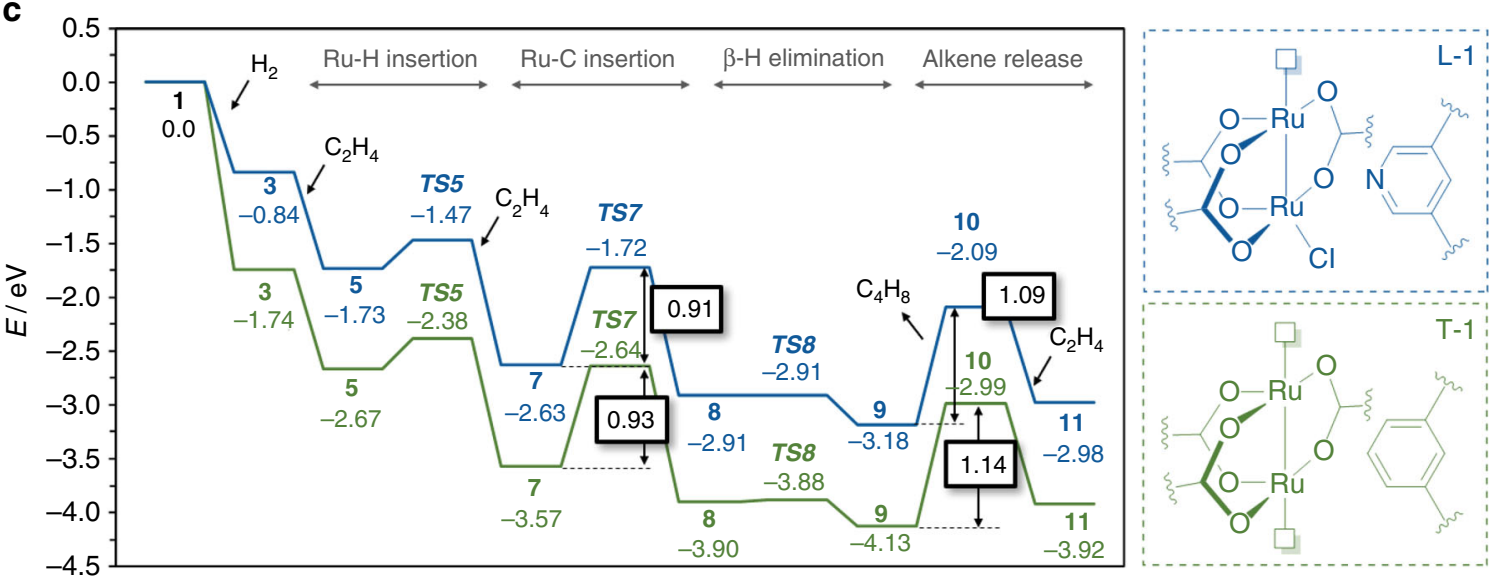

Reaction coordinate

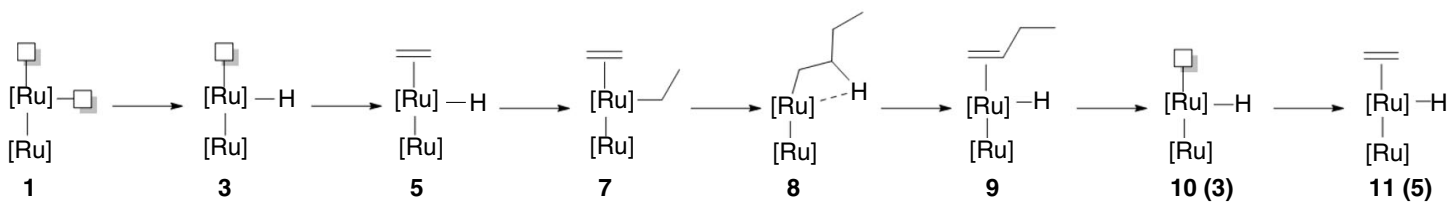

Fig. 4 Effects of ligand- and thermal-engineered defects on catalytic activity. a Turnover frequencies per total Ru as a function of measured defects via ligand (blue) and thermal (green) approaches. b Turnover frequencies per active Ru as a function of measured defects via ligand (blue) and thermal (green) approaches. c Computed reaction mechanism and energy profile for ethylene dimerization via ligand- (L, blue) and thermal-engineered ( $\mathbf{T}$, green) defective MOFs

an energy barrier of $0.91 \mathrm{eV}$. Such C-C bond formation appears to be the rate-determining step, where ethyl intermediates are potential resting states of the catalytic cycle in line with in-situ FTIR (Supplementary Fig. 10). The butyl intermediate (8) quickly undergoes $\beta$-H elimination through a barrierless process via TS8 to form 1-butene (9). Direct desorption of 1-butene via 10 takes only $1.09 \mathrm{eV}$; alternatively, at high ethylene pressures, ethylene can directly substitute 1-butene from 9 to $11^{36}$. To evaluate entropic contributions, we estimate the relative Gibbs energies for the $\mathrm{C}-\mathrm{C}$ bond formation step, 7 to TS7, and the alkene desorption process, 9-10. The resulting Gibbs (electronic) energy barriers are $0.91(0.91)$ and $0.68(1.09) \mathrm{eV}$, respectively, which further supports the $\mathrm{C}-\mathrm{C}$ bond formation as the rate-determining step of the catalytic cycle. We also studied the reaction mechanism using a thermal-engineered defective node. Figure $4 \mathrm{c}$ shows the model used in the calculations T-1 (Supplementary
Fig. 26) and the reaction profile in green. Similar energies were observed, with a barrier of $0.93 \mathrm{eV}$ (cf. $0.91 \mathrm{eV}$ ) for the C-C bond-forming step and $1.14 \mathrm{eV}$ (cf. $1.09 \mathrm{eV}$ ) for alkene desorption. The kinetic resemblance between ligand- and thermalengineered active sites toward dimerization is in line with previous experimental results (Fig. $4 \mathrm{a}, \mathrm{b}$ ).

The dimerization mechanism in Fig. 4c takes place on one metal atom, which allows defining TOFs per $\mathrm{Ru}$ atom per defective node (Figs. 2a and 4b). To further explore the role of the second metal, we prepared a periodic structure with a node containing only one $\mathrm{Ru}$ atom (Supplementary Fig. 30) and computed the desorption of 1-butene. Interestingly, we found a significantly higher value of $1.74 \mathrm{eV}$, compared to $1.09 \mathrm{eV}$ for the bimetallic node. It seems that the second metal plays a key electronic role favoring the alkene desorption. Bader analyses located positive charges of $+0.95\left|\mathrm{e}^{-}\right|$on $\mathrm{Ru}$ in the bimetallic 
model and $+1.22\left|\mathrm{e}^{-}\right|$on $\mathrm{Ru}$ in the monometallic model. The higher charge of the latter is in line with the more energydemanding desorption step. To further highlight the unique nature of the bimetallic active site, we attached mononuclear $\mathrm{Ru}$ and $\mathrm{Ni}$ species to bipyridine linkers in $(\mathrm{Zr}) \mathrm{UiO}-67-(\mathrm{Bpy})^{37,38}$. However, under our activator-free conditions, no dimerization products were experimentally observed. These results explain how the active site controls the dimerization selectivity via: (i) the slower rate of ethylene insertion into $\mathrm{Ru}$-alkyl groups (ca. $0.9 \mathrm{eV}$ via TS7) compared to chain termination (barrierless step via TS8) ${ }^{15}$ and (ii) facile alkene desorption ( $c a .1 .1 \mathrm{eV}$ from 9 to 10). The first one is due to the engineered defect (via ligand or thermal approaches), and the second one arises from the bimetallic nature of the MOF node. Such facile desorption is further enhanced in the presence of a solvating environment, as shown below.

Stability of MOF catalysts under intrapore condensation. After characterization and reactivity studies, we next evaluate the stability of these catalysts during ethylene dimerization with respect to reaction conditions. Figure 5a shows ethylene dimerization TOFs for $\mathrm{H}_{2}$-activated $\mathrm{MOF}_{\mathrm{L} 25}$ as a function of systematic changes in temperature (at constant $4.2 \mathrm{MPa}$ ) and ethylene pressure (at constant $50^{\circ} \mathrm{C}$ ). Stable TOFs are achieved at temperatures below $60^{\circ} \mathrm{C}$ (at $4.2 \mathrm{MPa}$ ) or pressures above $3.3 \mathrm{MPa}$ (at $\left.50^{\circ} \mathrm{C}\right)$. However, high temperatures $\left(>60^{\circ} \mathrm{C}\right.$, $4.2 \mathrm{MPa})$ or low pressures $\left(<3.6 \mathrm{MPa}, 50^{\circ} \mathrm{C}\right)$ lead to fast deactivation rates. Such deactivation occurs via the irreversible binding of oligomer products in secondary reactions of primary dimer products ${ }^{21}$, as evidenced by the curved shape of ethylene dimerization rate data at high ethylene conversion $\left(100^{\circ} \mathrm{C}\right.$ in Fig. 5a).

Figure $5 \mathrm{~b}$ shows first-order deactivation constants $\left(k_{\mathrm{d}}\right)$ as a function of ethylene relative saturation pressures $\left(P / P_{s a t}\right)$. Deactivation is accurately measured by $k_{\mathrm{d}}$ within small changes in conversion for $\mathrm{MOF}_{\mathrm{L} 25}$. Figure $5 \mathrm{~b}$ shows a continuous increase in $k_{\mathrm{d}}$ values below $P / P_{\text {sat }}$ of 0.4 , whereas deactivation is undetectable at $P / P_{\text {sat }}$ above 0.4 . Such reaction conditions and the narrow micropores of $\mathrm{MOF}_{\mathrm{L} 25}(1.5 \mathrm{~nm}$ diameter) suggest that active site stabilization is related to the intrapore condensation of ethylene molecules. We use $\mathrm{N}_{2}$ uptakes as surrogate to estimate ethylene intrapore condensation at reaction conditions (Supplementary Fig. 3) ${ }^{21}$. These analyses indicate that kinetically-relevant pores are liquid-filled at $P / P_{\text {sat }}$ above 0.4 . Condensation within MOF pores also leads to very high selectivity for $\mathrm{C}_{4}$ among products (>99\%) and 1-butene (primary $\mathrm{C}_{4}$ product, Supplementary Fig. 6), as liquid ethylene promotes the desorption of bound alkenes by substitution and prevents the formation of larger oligomers. To support such claim, we estimated the Gibbs energy difference associated with the ligand exchange from 9 to $\mathbf{1 1}$ (Fig. 4c) using reported entropies in gas and liquid phases ${ }^{39}$. The electronic energy difference to exchange 1 -butene by ethylene is endothermic by $0.20 \mathrm{eV}$. The resulting Gibbs energy differences in low-pressure (ethylene in gas phase) and high-pressure (ethylene in liquid phase to model intrapore condensation) are +0.01 and $-0.33 \mathrm{eV}$, respectively. The exoergicity of the process only under intrapore condensation conditions further proves the benefits of our experimental protocol.

Although $\mathrm{MOF}_{\mathrm{L} 25}$ starts to deactivate at $P / P_{\text {sat }}$ below 0.4 , it can be regenerated in $\mathrm{H}_{2}$ at $150{ }^{\circ} \mathrm{C}$ (Supplementary Fig. 7). Such mild conditions are more feasible than high temperatures and oxidizing environments used in typical catalyst regeneration procedures. This suggests that the regeneration mechanism proceeds through $\mathrm{Ru}$-catalyzed hydrogenation of bound alkenes rather than oligomer-desorption pathways.

The long-term stable rates, enabled by controlled intrapore ethylene condensation, indicate that the crystalline and porous structure of MOFs is maintained during catalytic conditions or regeneration steps. Such enhanced stability is independent of the synthetic protocol to create catalytic sites. Figure $5 \mathrm{c}$ shows turnover numbers (TONs) under intrapore liquid ethylene regime for ligand- $\left(\mathrm{MOF}_{\mathrm{L} 25}\right.$ and $\mathrm{MOF}_{\mathrm{L} 10} \mathrm{H}_{2}$-activated at $150^{\circ}$ C) and thermal-engineered $\left(\mathrm{MOF}_{\mathrm{L} 0}\right.$ pre-treated at $300{ }^{\circ} \mathrm{C}$ in $\mathrm{N}_{2}$ ) catalysts, with values of 13,000 . Our TON results outstand over reported $\mathrm{Ru}$-based $\mathrm{MOF}$ catalysts ${ }^{24}$ and are comparable to the 16,000 reported for state-of-the-art Ni-MOF catalysts ${ }^{12}$. Both ligand and thermal approaches lead to materials with remarkable stability, showing a mean life of one order of magnitude larger than Ni-MOF systems requiring co-catalysts or organic solvents ${ }^{12}$

In summary, we have developed a method for tailoring MOF defects via thermal-based protocols, resulting in defective nodes that behave as well-defined active sites for ethylene dimerization with remarkable activity (TOF of $c a .200 \mathrm{~h}^{-1}$ ) and high selectivity (99\% to 1-butene). Moreover, we demonstrate that working under reactant intrapore condensation regime within thermal-engineered defective MOFs provides outstanding stability $(>120 \mathrm{~h})$ to these catalytic systems (TON of 13,000). Such enhanced stability represents a significant advancement in the field of synthesis and performance of porous catalysts for ethylene dimerization reactions. Due to the absence of co-catalysts and solvents, such intrapore condensation effects in narrow-pore MOFs open
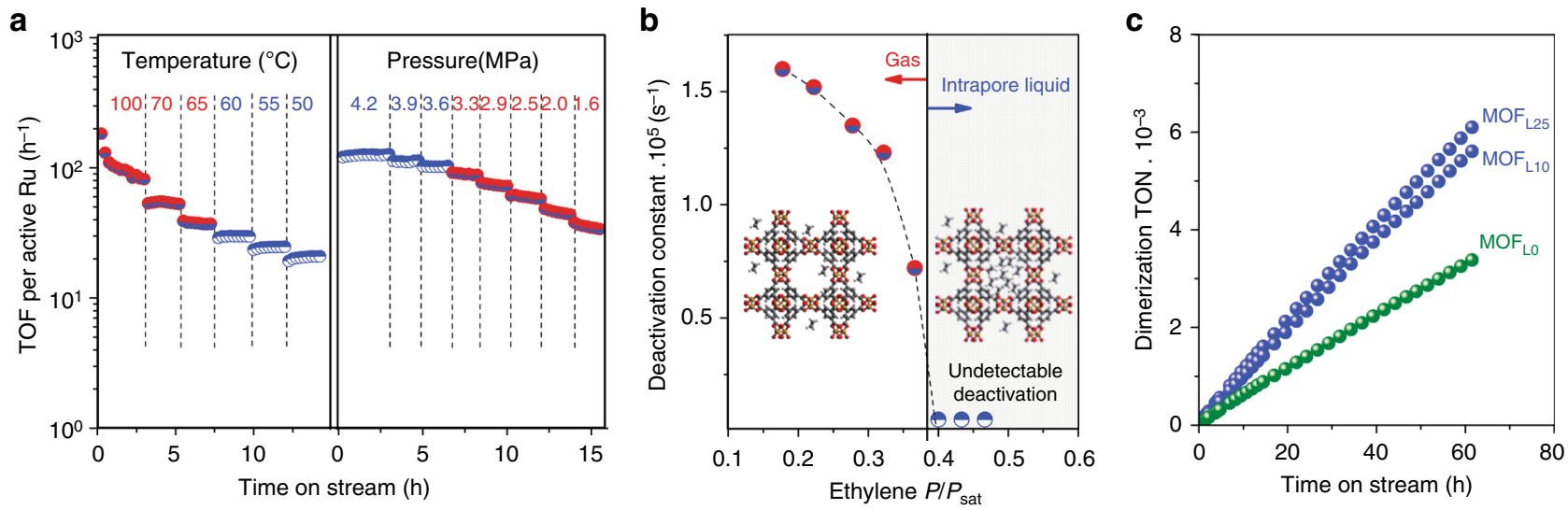

Fig. 5 Stability of MOF catalysts. a Turnover frequencies per active Ru as a function of temperature at $4.2 \mathrm{MPa}$ ethylene and pressure at $50{ }^{\circ} \mathrm{C}$. $\mathbf{b}$ Firstorder deactivation constants, derived from ethylene pressure changes in (a), as a function of ethylene relative saturation pressure $\left(P / P_{\text {sat }}\right)$ within $M O F_{L 25}$. c Long-term stability during ethylene dimerization at $4.2 \mathrm{MPa}$ ethylene and $50^{\circ} \mathrm{C}$ for $\mathrm{MOF}_{\mathrm{L} 25}, \mathrm{MOF}_{\mathrm{L} 10}$, and $\mathrm{MOF}_{\mathrm{LO}}$ 
exciting opportunities for the design of competitive procedures in terms of process intensification, safety, and production costs in other reactions involving gaseous reactants and structured catalysts.

\section{Methods}

MOF synthesis. $(\mathrm{Ru})$ HKUST-1 containing $0 \%\left(\mathrm{MOF}_{\mathrm{LO}}\right), 10 \%\left(\mathrm{MOF}_{\mathrm{L} 10}\right), 25 \%$ $\left(\mathrm{MOF}_{\mathrm{L} 25}\right)$, and $50 \%\left(\mathrm{MOF}_{\mathrm{L} 50}\right)$ of ligand-engineered defects were prepared by combining the appropriate mixture of organic ligands 1,3,5-benzenetricarboxylic acid and pyridine-3,5-dicarboxylic acid with Ru precursor $\left[\mathrm{Ru}_{2}\left(\mathrm{CH}_{3} \mathrm{COO}\right)_{4} \mathrm{Cl}\right]$, under solvothermal conditions at $160^{\circ} \mathrm{C}$ according to literature ${ }^{23}$. In a typical synthesis, $1 \mathrm{~g}$ of Ru precursor, $600 \mathrm{mg}$ of the selected mixture of organic ligand, $5 \mathrm{~mL}$ of acetic acid and $25 \mathrm{~mL}$ of $\mathrm{H}_{2} \mathrm{O}$ were loaded into a $100-\mathrm{mL}$ autoclave and heated at $160^{\circ} \mathrm{C}$ for $24 \mathrm{~h}$. The resulting powder was thoroughly washed with $\mathrm{H}_{2} \mathrm{O}$ in a filtration funnel and purified in a Soxhlet apparatus with $\mathrm{MeOH}$. All the samples were evacuated at $150{ }^{\circ} \mathrm{C}$ under vacuum.

Ru precursor $\left[\mathrm{Ru}_{2}\left(\mathrm{CH}_{3} \mathrm{COO}\right)_{4} \mathrm{Cl}\right]$ was prepared by mixing $10 \mathrm{~g}$ of $\mathrm{RuCl}_{3} \cdot x \mathrm{H}_{2} \mathrm{O}$ (40 wt.\%Ru) and $12 \mathrm{~g}$ of $\mathrm{LiCl}$ (anhydrous), previously evacuated at $80^{\circ} \mathrm{C}$ overnight in a vacuum oven, with $70 \mathrm{~mL}$ of acetic anhydride and $350 \mathrm{~mL}$ of glacial acetic acid. The mixture was stirred and refluxed for 2-4 days until the solution turned into reddish color. After cooling down, the Ru precursor was collected by filtration and was thoroughly washed with acetone.

Ethylene dimerization reactivity tests. Ethylene dimerization rates to butene products were measured in a high-pressure tubular reactor integrated in a fullyautomated lab-scale reaction unit. As-prepared MOF samples $(50 \mathrm{mg})$ were diluted with inert $\mathrm{SiO}_{2}$ (1:20 mass, Davisil-62, Sigma-Aldrich). Activation tests on ligandengineered MOF samples were carried out in a flow of inert $\left(\mathrm{N}_{2}, 2.0 \mathrm{~cm}^{3} \mathrm{~g}^{-1} \mathrm{~s}^{-1}\right.$, $99.999 \%$, Air Liquide) and oxidizing $\left(\mathrm{O}_{2}, 2.0 \mathrm{~cm}^{3} \mathrm{~g}^{-1} \mathrm{~s}^{-1}\right)$ or reducing environment $\left(\mathrm{H}_{2}, 99.9 \%, 2.0 \mathrm{~cm}^{3} \mathrm{~g}^{-1} \mathrm{~s}^{-1}\right)$ depending on the defect formation temperature and conditions. Kinetic isotope effects were evaluated using $\mathrm{D}_{2}$ ( $99 \%$, Air Liquide) as activator instead of $\mathrm{H}_{2}$. Thermal-engineered MOF samples were treated in $\mathrm{N}_{2}$ for $1 \mathrm{~h}$ at each reaction temperature. Prior to each catalytic test, the reactor was flushed with $\mathrm{N}_{2}$ before cooling to reaction temperature, initially pressurized in $\mathrm{N}_{2}$ until desired setpoint and ethylene (99.9\%, Air Liquide) was introduced at $10-20 \mathrm{~mol} \mathrm{~g}^{-1} \mathrm{~h}^{-1}$. Temperatures were measured with a K-type thermocouple (K-type, Omega) and controlled electronically. Pressure was electronically controlled with a servometer. The concentrations of ethylene and products were measured by flame ionization detection after chromatography separation (Agilent 6890; HP-5 methyl silicone). First-order deactivation constants $\left(k_{\mathrm{d}}\right)$ were measured from rate values $(r)$ in a specific time interval $(t)$ :

$$
\frac{r}{r_{0}}=-\exp \left[k_{\mathrm{d}}\left(t-t_{0}\right)\right]
$$

$\mathbf{N}_{\mathbf{2}}$ sorption isotherms. MOF samples were analyzed in a Micromeritics ASAP (Accelerated Surface Area and Porosimetry) 2020 System. Samples were weighted into tubes with seal frits and degassed under vacuum $(<500 \mu \mathrm{m} \mathrm{Hg})$ with heating. Samples were initially heated at $150^{\circ} \mathrm{C}$ and held for $4 \mathrm{~h}$, and finally cooled to room temperature and backfilled with $\mathrm{N}_{2}$. The samples were re-weighted before analysis. The analysis adsorptive was $\mathrm{N}_{2}$ at $77 \mathrm{~K}$. A multi-point BET surface area was determined from 6 measurements at relative pressures $\left(P / P_{\text {sat }}\right)$ ranging from 0.05 to 0.30 . Single point adsorption total pore volume was measured near saturation pressure $\left(P_{\text {sat }} \approx 770 \mathrm{mmHg}\right.$ ). Adsorption average pore width was also calculated. Pore size distribution plot was determined by Horvath-Kawazoe method using the Cylinder Pore Geometry (Saito-Foley) with Cheng-Yang Correction.

X-ray diffraction. XRD was used to study the crystalline structure of the MOF catalyst. XRD patterns were recorded using a Panalytical Empyrean X-ray diffractometer with $\mathrm{Cu} K a$ radiation $(\lambda=1.54778 \AA)$. The samples were prepared by filling the holder with the dry powder. Crystalline phase stability was investigated using an XRK900 high temperature oven chamber. Sample was first heated in the chamber from 25 to $800^{\circ} \mathrm{C}$ with a heating rate of $3^{\circ} \mathrm{C} / \mathrm{min}$. Diffraction patterns were measured throughout the whole heat treatment using $\mathrm{Cu} \mathrm{Ka} \mathrm{X}$-ray radiation with a wavelength of $1.5418 \AA$ and a $2 \theta$ range of $4.5^{\circ}-60^{\circ}$. Each pattern was measured for $4 \mathrm{~min}$ using a step size and count time of $2 \theta=0.0263^{\circ}$ and $147 \mathrm{~s} / \mathrm{step}$, respectively.

Fourier Transform Infrared Spectroscopy. In-situ FTIR analyses were carried out in a diffuse reflectance cell (Harrick) using a Bruker Vertex V70 module equipped with a liquid-nitrogen cooled MCT detector. Samples were sieved into fine powders $(<30 \mu \mathrm{m}$ particle size) and treated using same MOF activation procedures as described in main text in $\mathrm{N}_{2}$ or $\mathrm{H}_{2}$. Temperature was controlled with a Harrick module. $\mathrm{CO}$ adsorption experiments were carried out using $1 \% \mathrm{CO}$ in He between -80 and $30^{\circ} \mathrm{C}$, but given the remarkable binding strength of $\mathrm{CO}$ onto $\mathrm{Ru}-\mathrm{H}$ species, the spectra after $\mathrm{CO}$ adsorption are shown at $30^{\circ} \mathrm{C}$. Ethylene was also introduced at $50^{\circ} \mathrm{C}$ at same reaction conditions but at atmospheric pressure. All IR spectra are measured in $\mathrm{N}_{2}$ to avoid signal-disturbance for gas-phase $\mathrm{H}_{2}$ or CO.
$\mathbf{H}_{2}$-temperature programmed reduction. $\mathrm{H}_{2}$-TPR measurements of MOF catalysts were performed using an AutoChem II 2920 reactor (Micromeritics) equipped with a built-in TCD detector, and with the reactor downstream connected to a benchtop quadrupole mass spectrometer (TA). To mimic the MOF activation procedures as described in manuscript in $\mathrm{N}_{2}$ or $\mathrm{H}_{2}, 100 \mathrm{mg}$ sample was first degassed at $200^{\circ} \mathrm{C}$ for $1 \mathrm{~h}$ in $\mathrm{He}(50 \mathrm{~mL} / \mathrm{min})$, and then treated at $150^{\circ} \mathrm{C}$ for $1 \mathrm{~h}$ with $\mathrm{H}_{2}(50 \mathrm{~mL} / \mathrm{min})$. The TCD calibration was performed with $\mathrm{H}_{2}$ concentrations varied from 0 to $100 \%$ in $\mathrm{Ar}$ and a background test with an empty reactor at the same reaction condition was performed to create a baseline.

Thermogravimetric analyses (TGA) and mass spectrometry (MS). TGA-MS analyses of the MOF catalysts were performed using a TA Q500 unit coupled to a benchtop quadrupole mass spectrometer (TA).

XPS measurements. X-ray Photoelectron Spectroscopy (XPS) was performed using a monochromatized $\mathrm{Al} \mathrm{Ka}$ source $(\mathrm{h} v=1486.6 \mathrm{eV})$, operated at $225 \mathrm{~W}$, on a Kratos Axis Ultra DLD with a pass energy for narrow scan spectra of $20 \mathrm{eV}$, corresponding to an instrument resolution of $\sim 600 \mathrm{meV}$. Survey spectra were collected with a pass energy of $80 \mathrm{eV}$. Spectral fitting was performed using Casa XPS analysis software. Spectral positions were corrected by shifting the primary $\mathrm{C}$ $1 \mathrm{~s}$ core level position to $285.0 \mathrm{eV}$, and curves were fitted with quasi-Voigt lines following Shirley background subtraction.

Computational details. All calculations reported in the manuscript were performed at periodic DFT level using the Vienna Ab-initio Simulation Package (VASP) $^{40,41}$. The PBE functional ${ }^{42}$ was used together with Grimme's D2 dispersion scheme $^{43}$ and modified parameters for transition metals ${ }^{44}$. Core electrons were described by projector augmented wave (PAW $)^{45}$ and valence electrons in plane waves with a kinetic energy cutoff of $450 \mathrm{eV}$. The Brillouin zone was sampled at the $\Gamma$-point through the Monkhorst-Pack method ${ }^{46}$. Transition states were located with the climbing image nudged elastic band method ${ }^{47}$. The assessment of the minima and transition states was performed by diagonalizing the numerical Hessian matrix obtained by $\pm 0.015 \AA$ displacements. Selected cluster calculations were computed at the DFT level using Gaussian09 for benchmark purposes (Supplementary Table 5). All inputs and final structures can be found in the ioChem-BD repository ${ }^{48,49}$.

\section{Data availability}

The data that support this article and other findings are available from the corresponding authors upon request. The computational data can be freely accessed through the ioChem-BD repository (https://doi.org/10.19061/iochem-bd-1-83).

Received: 13 February 2019 Accepted: 11 April 2019

Published online: 06 May 2019

\section{References}

1. Gollwitzer, A., Dietel, T., Kretschmer, W. P. \& Kempe, R. A broadly tunable synthesis of linear a-olefins. Nat. Comm. 8, 1226 (2017).

2. Chen, C. Designing catalysts for olefin polymerization and copolymerization: beyond electronic and steric tuning. Nat. Rev. Chem. 2, 6-14 (2018).

3. Furukawa, H., Cordova, K. E., O'Keeffe, M. \& Yaghi, O. M. The chemistry and applications of metal-organic frameworks. Science 341, 1230444 (2013).

4. Rogge, S. M. J. et al. Metal-organic and covalent organic frameworks as singlesite catalysts. Chem. Soc. Rev. 46, 3134-3184 (2017).

5. Cui, X., Li, W., Ryabchuk, P., Junge, K. \& Beller, M. Bridging homogeneous and heterogeneous catalysis by heterogeneous single-metal-site catalysts. Nat. Catal. 1, 385-397 (2018).

6. Luz, I., Llabres i Xamena, F. X. \& Corma, A. Bridging homogeneous and heterogeneous catalysis with MOFs: "Click" reactions with $\mathrm{Cu}-\mathrm{MOF}$ catalysts. J. Catal. 276, 134-140 (2010).

7. Fang, Z., Bueken, B., De Vos, D. E. \& Fischer, R. A. Defect-engineered metal-organic frameworks. Angew. Chem. Int. Ed. 54, 7234-7254 (2015).

8. Dissegna, E., Epp, K., Heinz, W. R., Kieslich, G. \& Fischer, R. A. Defective metal-organic frameworks. Adv. Mater. 30, 1704501 (2018).

9. Canivet, J., Vandichel, M. \& Farrusseng, D. Origin of highly active metal-organic framework catalysts: defects? Defects! Dalton Trans. 45, 4090-4099 (2016).

10. Zhang, W. et al. Impact of synthesis parameters on the formation of defects in HKUST-1. Eur. J. Inorg. Chem. 925-931 (2017)

11. Sholl, D. S. \& Lively, R. P. Defects in metal-organic frameworks: challenge or opportunity? J. Phys. Chem. Lett. 6, 3437-3444 (2015).

12. Madrahimov, S. T. et al. Gas-phase dimerization of ethylene under mild conditions catalyzed by MOF materials containing (bpy) $\mathrm{Ni}^{\mathrm{II}}$ complexes. ACS Catal. 5, 6713-6718 (2015). 
13. Li, Z. Schweitzer, et al. Sintering-resistant single-site nickel catalyst supported by metal-organic framework. J. Am. Chem. Soc. 138, 1977-1982 (2016).

14. Liu, J. et al. Beyond the active site: Tuning the activity and selectivity of a metal-organic framework-supported $\mathrm{Ni}$ catalyst for ethylene dimerization. J. Am. Chem. Soc. 140, 11174-11178 (2018).

15. Metzger, E. D., Brozek, C. K., Comito, R. J. \& Dincă, M. Selective dimerization of ethylene to 1-butene with a porous catalyst. ACS Cent. Sci. 2, 148-153 (2016).

16. Ji, P. et al. Transformation of metal-organic framework secondary building units into hexanuclear $\mathrm{Zr}$-alkyl catalysts for ethylene polymerization. J. Am. Chem. Soc. 139, 11325-11328 (2017).

17. Metzger, E. D., Comito, R. J., Hendon, C. H. \& Dincă, M. Mechanism of single-site molecule-like catalytic ethylene dimerization in Ni-MFU-4l. J. Am. Chem. Soc. 139, 757-762 (2017).

18. Canivet, J., Aguado, S., Schuurman, Y. \& Farrusseng, D. MOF-supported selective ethylene dimerization single-site catalysts through one-pot postsynthetic modification. J. Am. Chem. Soc. 135, 4195-4198 (2013).

19. Mlinar, A. N. et al. Selective propene oligomerization with nickel(II)-based metal-organic frameworks. ACS Catal. 4, 717-721 (2014).

20. Metzger, E. D. et al. Highly selective heterogeneous ethylene dimerization with a scalable and chemically robust MOF catalyst. ACS Sustain. Chem. Eng. 7, 6654-6661 (2019).

21. Agirrezabal-Telleria, I. \& Iglesia, E. Stabilization of active, selective, and regenerable Ni-based dimerization catalysts by condensation of ethene within ordered mesopores. J. Catal. 352, 505-514 (2017).

22. Marx, S., Kleist, W. \& Baiker, A. Synthesis, structural properties, and catalytic behavior of Cu-BTC and mixed-linker Cu-BTC-PyDC in the oxidation of benzene derivatives. J. Catal. 281, 76-87 (2016).

23. Kozachuk, O. et al. Multifunctional, defect-engineered metal-organic frameworks with ruthenium centers: sorption and catalytic properties. Angew. Chem. Int. Ed. 53, 7058-7062 (2014).

24. Zhang, W. et al. Ruthenium metal-organic frameworks with different defect types: Influence on porosity, sorption, and catalytic properties. Chem. Eur. J. 22, 14297-14307 (2016).

25. Bullock, R. M. \& Helm, M. L. Molecular electrocatalysts for oxidation of hydrogen using earth-abundant metals: Shoving protons around with proton relays. Acc. Chem. Res. 48, 2017-2026 (2015).

26. Fiorio, J. L., López, N. \& Rossi, L. M. Gold-ligand-catalyzed selective hydrogenation of alkynes into cis-alkenes via $\mathrm{H}_{2}$ heterolytic activation by frustrated Lewis Pairs. ACS Catal. 7, 2973-2980 (2017).

27. Fiorio, J. L. et al. Accessing frustrated Lewis pair chemistry through robust Gold@ N-doped carbon for selective hydrogenation of alkynes. ACS Catal. 8, 3516-3524 (2018).

28. Noei, H. et al. CO adsorption on a mixed-valence ruthenium metal-organic framework studied by UHV-FTIR spectroscopy and DFT calculations. J. Phys. Chem. C. 117, 5658-5666 (2013).

29. Smith, G., Cole-Hamilton, D. J., Thornton-Pett, M. \& Hursthouse, M. B. The preparation and characterisation of cationic formyl complexes of ruthenium (II), crystal and molecular structure of the complex trans-bis[1,2-bis (diphenylphosphino)ethane-PP']carbonyl (deuterioformyl)ruthenium(II) hexafluoroantimonate-dichloromethane(1/1). J. Chem. Soc., Dalton Trans. 0, 2501-2507 (1983).

30. Matsubu, J. C., Yang, V. N. \& Christopher, P. Isolated metal active site concentration and stability control catalytic $\mathrm{CO}_{2}$ reduction selectivity. J. Am. Chem. Soc. 137, 3076-3084 (2015).

31. Lee, K. J., Lee, J. H., Jeoung, S. \& Moon, H. R. Transformation of metal-organic frameworks/coordination polymers into functional nanostructured materials: experimental approaches based on mechanistic insights. Acc. Chem. Res. 50, 2684-2692 (2017).

32. Winter, K. \& Barton, D. The thermal decomposition of benzoic acid. Can. J. Chem. 48, 3797-3801 (1970).

33. Yoon, J. W. et al. Controlled reducibility of a metal-organic framework with coordinatively unsaturated sites for preferential gas sorption. Angew. Chem. Int. Ed. 49, 5949-5952 (2010).

34. Bernales, V. et al. Computationally guided discovery of a catalytic cobaltdecorated metal-organic framework for ethylene dimerization. J. Phys. Chem. C 120, 23576-23583 (2016).

35. Pellizzeri, S. et al. Catalytic descriptors and electronic properties of single-site catalysts for ethene dimerization to 1-butene, Catal. Today 312, 149-157 (2018).

36. Ye, J., Gagliardi, L., Truhlar, D. G. \& Cramer, C. J. Single Ni atoms and $\mathrm{Ni}_{4}$ clusters have similar catalytic activity for ethylene dimerization. J. Catal. 354, 278-286 (2017).

37. Øien, S. et al. Probing reactive platinum sites in UiO-67 zirconium metal-organic frameworks. Chem. Mater. 27, 1042-1056 (2015).
38. Gonzalez, M. I., Oktawiec, J. \& Long, J. R. Ethylene oligomerization in metal-organic frameworks bearing nickel(II) $2,2^{\prime}$-bipyridine complexes. Faraday Discuss. 201, 351-367 (2017).

39. NIST. NIST Chemistry WebBook, SRD 69, https://webbook.nist.gov/chemistry/.

40. Kresse, G. \& Furthmüller, J. Efficient iterative schemes for ab initio totalenergy calculations using a plane-wave basis set. Phys. Rev. B 54, 11169-11186 (1996).

41. Kresse, G. \& Furthmüller, J. Efficiency of ab-initio total energy calculations for metals and semiconductors using a plane-wave basis set. Comput. Mater. Sci. 6, 15-50 (1996)

42. Perdew, J. P., Burke, K. \& Ernzerhof, M. Generalized gradient approximation made simple. Phys. Rev. Lett. 77, 3865-3868 (1996).

43. Grimme, S. Semiempirical GGA-type density functional constructed with a long-range dispersion correction. J. Comp. Chem. 27, 1787-1799 (2006).

44. Almora-Barrios, N., Carchini, G., Błoński, P. \& López, N. Costless derivation of dispersion coefficients for metal surfaces. J. Chem. Theory Comput. 10, 5002-5009 (2014)

45. Kresse, G. \& Joubert, D. From ultrasoft pseudopotentials to the projector augmented-wave method. Phys. Rev. B 59, 1758-1775 (1999).

46. Monkhorst, H. J. Pack., J. D. Special points for Brillouin-zone integrations. Phys. Rev. B 13, 5188-5192 (1976).

47. Henkelman, G. \& Jónsson, H. Improved tangent estimate in the nudged elastic band method for finding minimum energy paths and saddle points. J. Chem. Phys. 113, 9978-9985 (2000).

48. Alvarez-Moreno, M. et al. Managing the computational chemistry big data problem: the ioChem-BD platform. J. Chem. Inf. Model. 55, 95-103 (2015).

49. Ortuño, M. A. Database ioChem-BD, https://doi.org/10.19061/iochem-bd-183.

\section{Acknowledgements}

This work was financially supported by the research fund from Basque Government (IT993-16) and RTI international funds. M.A.O. and N.L. acknowledge BSC-RES for generous computer resources (RES-QCM-2018-2-0020). M.A.O. acknowledges the "Juan de la Cierva-Incorporación" programme from MINECO (IJCI-2016-29762) and the "Beatriu de Pinós" programme from AGAUR (2017-BP-00039).

\section{Author contributions}

I.A.T. contributed to dimerization reactions; M.O.B. and I.G. contributed to IR measurements; I.L., M.S., and M. L. contributed to MOF synthesis and characterization (XRD, TGA-MS, and XPS); M.A.O. contributed to DFT computation and N. L. contributed to the manuscript writing. All authors contributed to the design of experiments and modeling.

\section{Additional information}

Supplementary Information accompanies this paper at https://doi.org/10.1038/s41467019-10013-6.

Competing interests: The authors declare no competing interests.

Reprints and permission information is available online at http://npg.nature.com/ reprintsandpermissions/

Journal peer review information: Nature Communications thanks the anonymous reviewer(s) for their contribution to the peer review of this work.

Publisher's note: Springer Nature remains neutral with regard to jurisdictional claims in published maps and institutional affiliations.

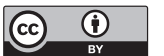

Open Access This article is licensed under a Creative Commons Attribution 4.0 International License, which permits use, sharing, adaptation, distribution and reproduction in any medium or format, as long as you give appropriate credit to the original author(s) and the source, provide a link to the Creative Commons license, and indicate if changes were made. The images or other third party material in this article are included in the article's Creative Commons license, unless indicated otherwise in a credit line to the material. If material is not included in the article's Creative Commons license and your intended use is not permitted by statutory regulation or exceeds the permitted use, you will need to obtain permission directly from the copyright holder. To view a copy of this license, visit http://creativecommons.org/ licenses/by/4.0/.

(C) The Author(s) 2019 